\title{
USPIO-enhanced magnetic resonance imaging of the knee in asymptomatic volunteers
}

\author{
Reiner, C S ; Lutz, A M ; Tschirch, F ; Froehlich, J M ; Gaillard, S ; Marincek, B ; Weishaupt, D
}

\begin{abstract}
The aim of this study was to compare signal characteristics of the synovium in knees of asymptomatic volunteers before and after intravenous administration of ultrasmall superparamagnetic iron oxide particles (USPIO). Ten knees of 10 asymptomatic volunteers were examined before and $36 \mathrm{~h}$ after intravenous administration of USPIO on a 1.5-T MR system using T1-weighted spin-echo, T2-weighted fast spin-echo, $2_{2}^{*}$-weighted gradient-echo (GRE), and short inversion time inversion-recovery sequences. In addition, synovial perfusion was measured using Gd-enhanced GRE imaging during the first imaging session. Images were analyzed qualitatively for any visual changes before and after USPIO administration. Signal-to-noise ratios (SNR) of the synovium were determined on unenhanced and USPIO-enhanced sequences. All MR images were reviewed for presence of any degenerative changes. Qualitative image analysis revealed no visually detectable changes of any knee joint before and after USPIO administration. The SNR values of the synovium on $\mathrm{T} 1 \mathrm{w}, \mathrm{T} 2 \mathrm{w}$, and $\mathrm{T} 2{ }^{*} \mathrm{w}$ images before and after USPIO administration showed no significant difference ( $\mathrm{T} 1, \mathrm{P}=0.86 ; \mathrm{T} 2, \mathrm{P}=0.95 ; \mathrm{T} 2 *, \mathrm{P}=0.86)$. None of the volunteers showed any relevant degenerative changes of the knee and synovial perfusion was within normal limits. In knees of asymptomatic volunteers without any relevant degenerative changes and normal synovial perfusion neither visual changes nor changes of SNR values of the synovium can be depicted after USPIO administration. This means that USPIO-enhanced MRI may be used for assessment of knee disorders with increased macrophage activity.
\end{abstract}

DOI: https://doi.org/10.1007/s00330-009-1343-4

Posted at the Zurich Open Repository and Archive, University of Zurich

ZORA URL: https://doi.org/10.5167/uzh-18189

Journal Article

Published Version

Originally published at:

Reiner, C S; Lutz, A M; Tschirch, F; Froehlich, J M; Gaillard, S; Marincek, B; Weishaupt, D (2009). USPIO-enhanced magnetic resonance imaging of the knee in asymptomatic volunteers. European Radiology, 19(7):1715-1722.

DOI: https://doi.org/10.1007/s00330-009-1343-4 


\author{
C. S. Reiner \\ A. M. Lutz \\ F. Tschirch \\ J. M. Froehlich \\ S. Gaillard \\ B. Marincek \\ D. Weishaupt
}

\section{USPIO-enhanced magnetic resonance imaging of the knee in asymptomatic volunteers}

Received: 24 August 2008

Accepted: 11 January 2009

Published online: 28 March 2009

(C) European Society of Radiology 2009

C. S. Reiner - A. M. Lutz - F. Tschirch

B. Marincek - D. Weishaupt $(\bowtie)$

Institute of Diagnostic Radiology,

Department of Radiology,

University Hospital Zurich,

Raemistrasse 100,

8091 Zurich, Switzerland

e-mail: dominik.weishaupt@usz.ch

Tel.: +41-44-2552900

Fax: +41-44-2554506

\section{A. M. Lutz}

Department of Radiology,

Stanford University School of Medicine,

Stanford, CA, USA

J. M. Froehlich

Guerbet,

Zurich, Switzerland

S. Gaillard

Guerbet,

Roissy CDG, France
Abstract The aim of this study was to compare signal characteristics of the synovium in knees of asymptomatic volunteers before and after intravenous administration of ultrasmall superparamagnetic iron oxide particles (USPIO). Ten knees of 10 asymptomatic volunteers were examined before and $36 \mathrm{~h}$ after intravenous administration of USPIO on a 1.5-T MR system using T1-weighted spinecho, T2-weighted fast spin-echo, $\mathrm{T} 2 *$-weighted gradient-echo (GRE), and short inversion time inversionrecovery sequences. In addition, synovial perfusion was measured using Gd-enhanced GRE imaging during the first imaging session. Images were analyzed qualitatively for any visual changes before and after USPIO administration. Signal-tonoise ratios (SNR) of the synovium were determined on unenhanced and USPIO-enhanced sequences. All MR images were reviewed for presence of any degenerative changes. Qualitative image analysis revealed no visually detectable changes of any knee joint before and after USPIO administration. The SNR values of the synovium on $\mathrm{T} 1 \mathrm{w}, \mathrm{T} 2 \mathrm{w}$, and $\mathrm{T} 2 * \mathrm{w}$ images before and after USPIO administration showed no significant difference (T1, $P=0.86$; T2, $P=0.95$; T2* $P=0.86$ ). None of the volunteers showed any relevant degenerative changes of the knee and synovial perfusion was within normal limits. In knees of asymptomatic volunteers without any relevant degenerative changes and normal synovial perfusion neither visual changes nor changes of SNR values of the synovium can be depicted after USPIO administration. This means that USPIO-enhanced MRI may be used for assessment of knee disorders with increased macrophage activity.

\section{Keywords Ultrasmall}

superparamagnetic iron oxide particles - Magnetic resonance imaging $\cdot$ Knee $\cdot$ Macrophages

\section{Introduction}

The potentials of cell-specific MR imaging (MRI) using superparamagnetic nanoparticles for imaging of musculoskeletal disorders have been recently recognized. Findings of several in vitro and in vivo studies have shown that superparamagnetic iron oxide particles (SPIO) and ultrasmall superparamagnetic iron oxide particles (USPIO) are phagocytosed by macrophages [1]. Therefore, large collections of macrophages in inflammatory tissues and the resulting signal changes may be detected by MRI on delayed T2-weighted or T2*-weighted sequences [2-7] in (U)SPIO-enhanced imaging.

Since macrophages play an important role in the pathogenesis of rheumatoid arthritis (RA) [8, 9], the technique is of particular interest in order to improve the diagnostic performance of imaging in this inflammatory joint disease. As the amount of macrophages residing within the synovium in RA is influenced by the grade of neoangiogenesis and resulting synovial 
hyperperfusion [10], the extent of signal changes on iron oxide-enhanced MR images may depend on the grade of synovial hyperperfusion. Several studies in animal models of antigen-induced arthritis have shown that both SPIO and USPIO allow specific detection of macrophage infiltration of the synovial membrane [2, $6,11,12]$. These results have led to the conclusion that iron oxide nanoparticles-enhanced MRI may also be useful for human applications in particular for the assessment of early stages of arthritis which are currently not sufficiently detectable by the current imaging modalities or for monitoring of disease activity $[6,13,14]$.

Despite the promising animal data, to the best of our knowledge, the USPIO-enhanced MRI for imaging of inflammatory joint disease has not been used in humans. However, before a new imaging technique is used in diseased patients it may be of interest to investigate asymptomatic volunteers in order to define normal findings and to exclude nonspecific signal effects. Therefore, the purpose of our study was to assess the signal characteristics of the synovium in knees of asymptomatic volunteers before and after intravenous administration of USPIO.

\section{Materials and methods}

\section{Volunteers}

Eleven volunteers (six females, five males; mean age, 35.7 years; range, 22-50 years) who met the inclusion criteria and consented to participate were included in the study. The study was approved by the Institutional Review Board, was notified to the national regulatory authorities, and written informed consent was obtained from each volunteer. Each participant was only included if there was no history of inflammatory joint disease, no history of knee surgery, no history of a relevant knee trauma nor knee pain in the last 6 months. The exclusion criteria were a general contraindication to MRI, a known previous reaction to MR contrast agents, drugs (including dextran) or food, pregnancy or hemochromatosis.

\section{Study design}

The volunteers underwent two imaging sessions. In each volunteer one knee was examined (the right knee in eight volunteers, the left knee in three volunteers). The first MRI session was performed as the baseline study before administration of USPIO (unenhanced imaging) and for acquisition of the synovial perfusion. In order to detect any kind of synovial hyperperfusion which could influence the characteristics of USPIO-enhanced imaging of the knee in otherwise healthy volunteers, synovial perfusion was measured. To acquire perfusion images an extracellular gadolinium (Gd)based contrast agent was administered intravenously as a bolus injection during the first MRI session. After finishing the first imaging session, USPIO was administered intravenously as a slow drip infusion (see below). The second MRI session (enhanced imaging) was performed $36 \mathrm{~h}$ after USPIO administration. During this second imaging session no additional contrast agent was administered.

\section{MR imaging}

MR imaging of the knee of each asymptomatic volunteer was performed on a 1.5-T MR system (Signa EchoSpeed EXCITE $^{\circledR}$ HD or HDx, GE Healthcare, Waukesha, Wisconsin, USA) using a dedicated phased-array knee coil. We chose to perform imaging on a 1.5-T system, since this represents the clinically most widely available field strength. The same MR machine and coil were used for both imaging sessions. The knee was imaged in the exact same position during both imaging sessions.

The imaging protocol for the first and the second imaging session included T1-weighted (T1w) spin-echo (SE) sequences, T2-weighted (T2w) fast SE (FSE) sequences, $\mathrm{T} 2 *$-weighted $(\mathrm{T} 2 * \mathrm{w})$ gradient-echo (GRE) sequences, and short inversion time inversion-recovery (STIR) sequences and is displayed in Table 1. MR imaging was performed in the transverse and sagittal plane for the $\mathrm{T} 1 \mathrm{w}, \mathrm{T} 2 \mathrm{w}$, and $\mathrm{T} 2 * \mathrm{w}$ sequences, and in the coronal plane for the STIR sequences.

At the end of the first imaging session a series of eleven multiphase fast GRE (FGRE) image sets (TR/TE, $100 / 14 \mathrm{msec}$; FOV, $160 \times 160 \mathrm{~mm}$; matrix, $256 \times 192$; number of signals acquired, 1) was obtained in transversal plane, with each image set consisting of four slices of 4-mm thickness at the level of the femoral condyles. After acquisition of the first image set Gd-DOTA (Dotarem ${ }^{\circledR}$, Guerbet, Roissy, France) was injected into a cubital vein while the volunteer remained in the same position and the remaining ten image sets were obtained with an update rate of one image set every $30 \mathrm{~s}$.

\section{Contrast agent}

To measure synovial perfusion $0.1 \mathrm{mmol}$ Gd-DOTA $/ \mathrm{kg}$ body weight (Dotarem, Guerbet, Roissy, France) was administered intravenously as bolus injection with a power injector (Spectris; Medrad, Indianola, Pa) at a flow rate of $3 \mathrm{ml} / \mathrm{s}$ followed by a $20-\mathrm{ml}$ saline flush during the first imaging session for the acquisition of the perfusion sequences.

The USPIO contrast agent used in this study was ferumoxtran-10 (Sinerem ${ }^{\mathbb{R}}$, Guerbet, Roissy, France) with an overall mean particle diameter of $20-30 \mathrm{~nm}$. The contrast agent (2.6 mg iron $/ \mathrm{kg}$ body weight corresponding to $45 \mu \mathrm{mol} / \mathrm{kg}$ body weight, diluted in $100 \mathrm{ml}$ of $0.9 \%$ saline solution) was administered intravenously as a slow drip infusion through a $0.2-\mu \mathrm{m}$ Sterifix ${ }^{\circledR}$ infusion filter set 
Table 1 MR imaging parameters for the first and second imaging session

\begin{tabular}{lllll}
\hline & T1w SE & T2w FSE & T2*w GRE & STIR \\
\hline Repetition time/echo time (ms) & $325 / 15.7$ & $3,300 / 85$ & $500 / 15$ & $3,975 / 34$ \\
Inversion time (ms) & - & - & - & 150 \\
Echo train length & - & 16 & - & $160 \times 160$ \\
Field of view (mm) & $160 \times 160$ & $160 \times 160$ & $256 \times 224$ & $160 \times 160$ \\
Matrix & $256 \times 224$ & $256 \times 224$ & 2 & $256 \times 192$ \\
Signals acquired & 2 & 2 & 25 & 2 \\
Flip angle (degrees) & - & - & $4 / 0.4$ & - \\
Slice thickness/gap (mm) & $4 / 0.4$ & $4 / 0.4$ & $0.63 \times 0.71 \times 4$ & $3 / 1$ \\
Voxel size (mm) & $0.63 \times 0.71 \times 4$ & $0.63 \times 0.71 \times 4$ & $0.63 \times 0.83 \times 3$ \\
\hline
\end{tabular}

at a flow rate of $3 \mathrm{ml} / \mathrm{min}$ directly after the first imaging session was completed. The total infusion time was approximately $30 \mathrm{~min}$. Potential adverse effects during contrast administration were noted.

Image analysis

For qualitative and quantitative image analysis all MR images were transferred to a dedicated, commercially available workstation (Advantage Workstation 4.2; GE Medical Systems, Buc, France). Qualitative image analysis was performed in a consensus reading by two radiologists in a blinded fashion. Both readers were blinded to the volunteer's names, age, sex, and any clinical information other than the inclusion criteria. Quantitative analysis with regard to the degree of synovial perfusion as well as signal changes following ferumoxtran-10 administration was performed separately by one radiologist (see below).

\section{Qualitative analysis}

Assessment of joint abnormalities MR studies were reviewed for signs of osteoarthritis such as cartilage defects and osteophytes in the medial and lateral tibiofemoral and patellofemoral joint compartments, tibial and femoral subchondral cysts, joint effusion, and for abnormalities of the medial and lateral menisci [15-18].

Meniscal abnormalities included intrasubstance degeneration and meniscal tears which were graded following the MR imaging criteria described by Crues et al. [19].

Assessment of visual changes following ferumoxtran-10 administration The readers evaluated pairwise unenhanced images of the first imaging session and enhanced images of the second imaging session with regard to the presence or absence of visual changes in the signal characteristics of the synovium and the synovial fluid between unenhanced and enhanced T1w SE, T2w FSE, and T2*w GRE images.

\section{Quantitative analysis}

Synovial perfusion The multiphase FGRE images were analyzed using the "Functool" software package (GE Medical Systems, Buc, France) installed on the workstation. On multiphase FGRE images defined round or elliptic regions of interest (ROI) between 5 and $10 \mathrm{~mm}^{2}$ were placed, one within the synovium and one within the muscle tissue of each knee joint. Because the synovium and the joint capsule could not be distinguished as separate anatomic structures they were considered a single structure for signal intensity (SI) measurements. The relative enhancement of the synovium (REs) and the muscle tissue (REm) at $t$ seconds was calculated according to the formula $R E_{t}=\left(S I_{t}-S I_{0}\right) / S I_{0} \times 100 \% . \mathrm{SI}_{0}$ and $\mathrm{SI}_{t}$ are defined as the SI before and $t$ seconds after Gd contrast injection.

Assessment of signal changes following ferumoxtran-10 administration On unenhanced and enhanced T1w SE, T2w FSE, and T2*w GRE images SI measurements were obtained by means of ROIs with a diameter of $1-5 \mathrm{~mm}^{2}$. Three ROIs were placed within comparable locations within the synovium. The mean values of the three ROIs were calculated for further analysis. In addition, the background noise was measured within three ROIs placed in a region of the image outside the knee. Signal-to-noise ratios (SNR) were calculated by dividing the mean of the measured SI of the synovium by the standard deviation of the background noise. The relative SNR changes between pre- and postcontrast $\mathrm{T} 1 \mathrm{w}, \mathrm{T} 2 \mathrm{w}$, and $\mathrm{T} 2{ }^{*} \mathrm{w}$ images were quantified using the following formula: $S N R_{\text {change }}=$ $\left[\left(S N R_{\text {postcontrast }}-S N R_{\text {precontrast }}\right) / S N R_{\text {precontrast }}\right] \times 100$.

\section{Statistical analysis}

The results of RE measurements of synovium and muscle tissue on perfusion images and the SNR values of the 
synovium on pre- and post-USPIO images are given as mean \pm standard deviation (SD). In addition, the difference between RE of synovium and muscle tissue at each timepoint $t$ was calculated in percent. The Wilcoxon signedrank test was used to compare the RE of the synovium and muscle tissue at each time-point $t$ on perfusion images and to compare the SNR values of the synovium before and after administration of USPIO. A $P$ value of less than 0.05 was considered to indicate a statistically significant difference.

The statistical analysis was performed using the SPSS Software (SPSS 12.0.1 Inc., Chicago, IL, USA).

\section{Results}

In 1 of $11(9 \%)$ volunteers moderate adverse effects occurred 2 min after the start of the USPIO infusion, including flush, perioral paresthesia, nausea, and near collapse. The infusion was stopped immediately and no enhanced images were obtained impeding further evaluation of this volunteer. Thus, the entire protocol with both imaging sessions could be completed in ten asymptomatic volunteers and a total of ten knees were available for analysis. In nine out of the remaining ten $(90 \%)$ volunteers, no subjective or objective adverse effects during administration of the contrast agents were reported. In one single volunteer $(10 \%)$, mild adverse effects (pruritus and urticaria) occurred following USPIO administration. Nevertheless, the second imaging session could be completed.

\section{Qualitative analysis}

\section{Assessment of joint abnormalities}

Significant signs of osteoarthritis were absent in all evaluated knees. The evaluation for signs of osteoarthritis revealed minor cartilage lesions in six knees $(60 \%)$. Osteophytes and subchondral cysts were seen in none of the knee joints. In one out of ten knee joints (10\%) a small joint effusion was present in the suprapatellar recess. Meniscal intrasubstance degeneration was found in four $(40 \%)$ knees (medial menisci) and a nondisplaced tear was found in two $(20 \%)$ knees (one lateral and one medial meniscus). In the knee with the nondisplaced tear of the lateral meniscus the medial meniscus showed a displaced tear in the posterior horn.

\section{Assessment of visual changes following ferumoxtran-10 administration}

Qualitative image analysis revealed no visual changes in the signal characteristics of the synovium and the synovial fluid of any of the knees between pre- and postcontrast $\mathrm{T} 1 \mathrm{w}, \mathrm{T} 2 \mathrm{w}$, and $\mathrm{T} 2 *_{\mathrm{w}}$ images (Fig. 1). The subjective findings of the qualitative analysis of signal characteristics were in accordance with the results of the quantitative analysis of pre- and postcontrast images.

\section{Quantitative analysis}

\section{Assessment of synovial perfusion}

The RE of synovial and muscular tissue was calculated for each time-point $t$, showing a mean maximum value of $25 \pm$ $12 \%$ (range, $7-44 \%$ ) for synovial tissue and a mean maximum value of $40 \pm 10 \%$ (range, 26-59\%) for muscular tissue. The synovium enhanced to a lesser degree than muscular tissue with an RE that was consistently lower by $17 \pm 14 \%(P<0.001)$. The course of the mean RE of the synovial and the muscular tissue of ten volunteers' knees following Gd-DOTA is shown in Fig. 2. Synovial and muscular tissue did not show any high early enhancement, followed by a late static enhancement, as one would expect in inflamed knee joints $[14,20]$. In conclusion these results did not reveal any evidence for synovial hyperperfusion in the evaluated knee joints.

\section{Assessment of signal changes following \\ ferumoxtran-10 administration}

The SNR values of the synovium as measured in each volunteer on unenhanced and enhanced $\mathrm{T} 1 \mathrm{w}, \mathrm{T} 2 \mathrm{w}$, and $\mathrm{T} 2 * \mathrm{~W}$ images are displayed in Table 2 . When the SNR values before and $36 \mathrm{~h}$ after USPIO administration were compared, no statistically significant differences were detected on T1w, T2 $\mathrm{w}$, and $\mathrm{T} 2 * \mathrm{w}$ images $(P=0.96, P=$ $0.96, P=0.80$ ). The mean relative SNR changes between unenhanced and enhanced images were $3.6 \% \pm 12.5$ on T $1 \mathrm{w}$ sequences, $2.5 \% \pm 13.5$ on $\mathrm{T} 2 \mathrm{w}$ sequences, and $0.7 \% \pm 16.9$ on $\mathrm{T} 2 * \mathrm{w}$ sequences.

\section{Discussion}

Increased perfusion of the synovial tissue due to neoangiogenesis as well as inflammatory cellular infiltration in affected joints are important characteristics of rheumatoid arthritis (RA) [9, 10, 14]. Among the involved inflammatory cells, macrophages play a pivotal role in the pathogenesis and continuance of RA. The number of macrophages accumulating in the synovial tissue of affected joints is known to positively correlate to grade of joint destruction, pain, and prognosis in RA $[8,21]$. An important novel class of disease-modifying drugs, anti-TNF- $\alpha$ agents, has been shown to mainly target macrophages and their cytokines [22]. More 

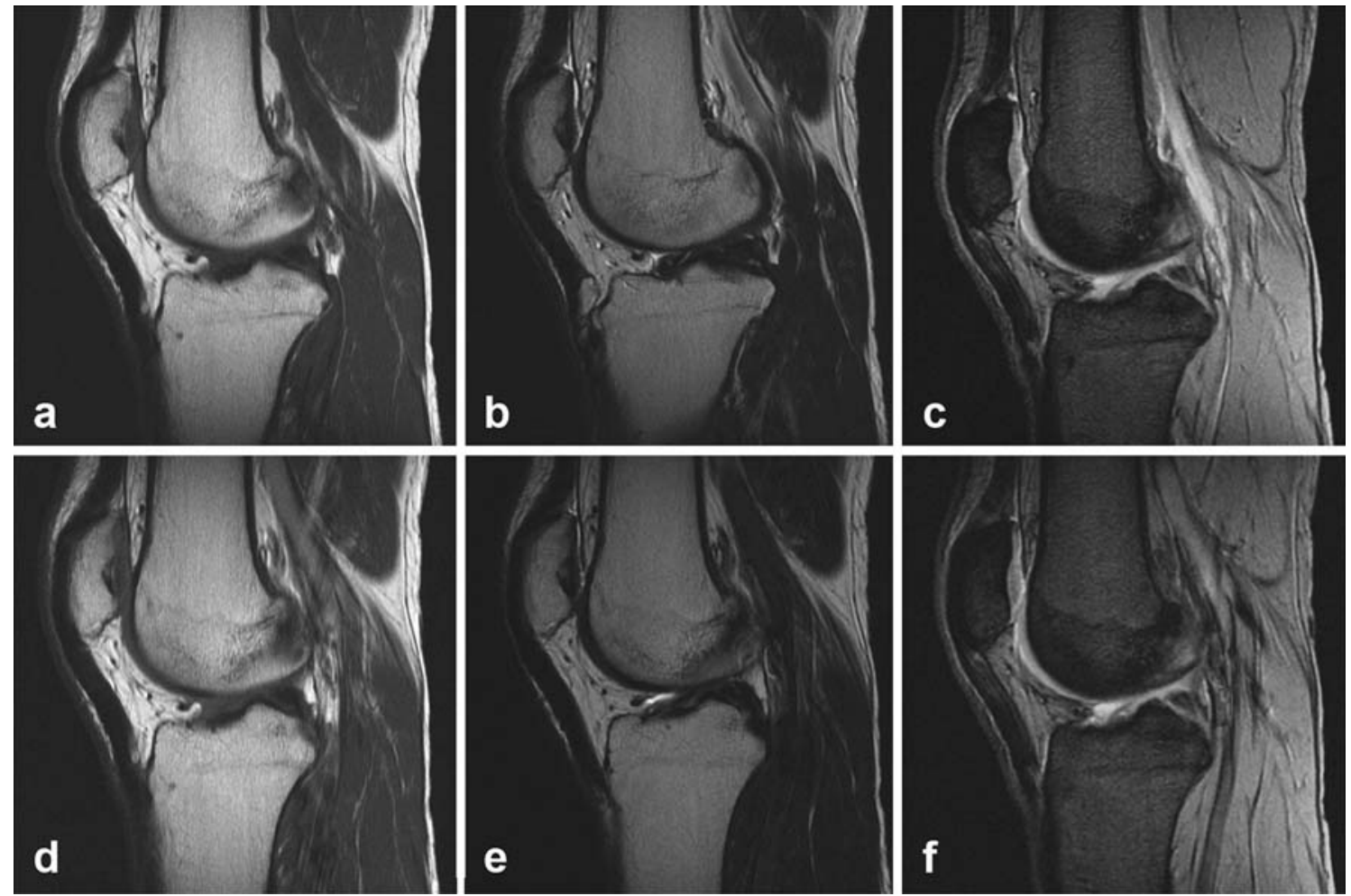

Fig. 1 Sagittal images of the knee of a 47-year-old asymptomatic volunteer before $(\mathbf{a}-\mathbf{c})$ and $36 \mathrm{~h}$ after $(\mathbf{d}, \mathbf{f})$ USPIO administration obtained in the following sequences: $\mathbf{a}$ and d, T1w SE (TR/TE, $325 / 15.7 \mathrm{~ms}$ ); b and e, T2w FSE (TR/TE, 3,300/85 ms); $\mathbf{c}$ and f, T2* ${ }^{\mathrm{w}}$ GRE (TR/TE, 500/15 ms). No visual changes in the signal characteristics of the synovium and the synovial fluid between pre-

recent therapy approaches, therefore, target neoangiogenesis to suppress inflammation and prevent irreversible joint destruction $[10,22-25]$. In order to balance risk and benefit as well as costs of this therapy strategy, sensitive and specific diagnostic imaging methods are and postcontrast $\mathrm{T} 1 \mathrm{w}, \mathrm{T} 2 \mathrm{w}$, and $\mathrm{T} 2{ }^{*} \mathrm{w}$ images were detected. The SNR values of the synovium measured on precontrast images were 18.6 on $\mathrm{T} 1 \mathrm{w}(\mathbf{a}), 17.1$ on $\mathrm{T} 2 \mathrm{w}(\mathbf{b})$, and 9.5 on $\mathrm{T} 2 * \mathrm{w}(\mathbf{c})$ sequences. On postcontrast images the SNR values of the synovium were 17.0 on $\mathrm{T} 1 \mathrm{w}(\mathbf{d}), 16.2$ on $\mathrm{T} 2 \mathrm{w}(\mathbf{e})$, and 8.0 on $\mathrm{T} 2 * \mathrm{w}(\mathbf{f})$ sequences

required for the detection of early inflammatory changes in active RA and for close therapy monitoring. For this purpose, imaging approaches capable of assessing synovial macrophage content and synovial perfusion may be beneficial in the therapy monitoring. The
Fig. 2 Mean relative enhancement (RE) of the synovial and the muscular tissue in each of the 11 image sets of the multiphase FGRE sequences acquired before (image number 1) and after (image numbers 2-11) GdDOTA administration. The curves illustrate the course of the mean RE of the synovium and the muscular tissue as measured in ten volunteers' knees, which show only moderate early relative enhancement of the synovial and muscular tissue

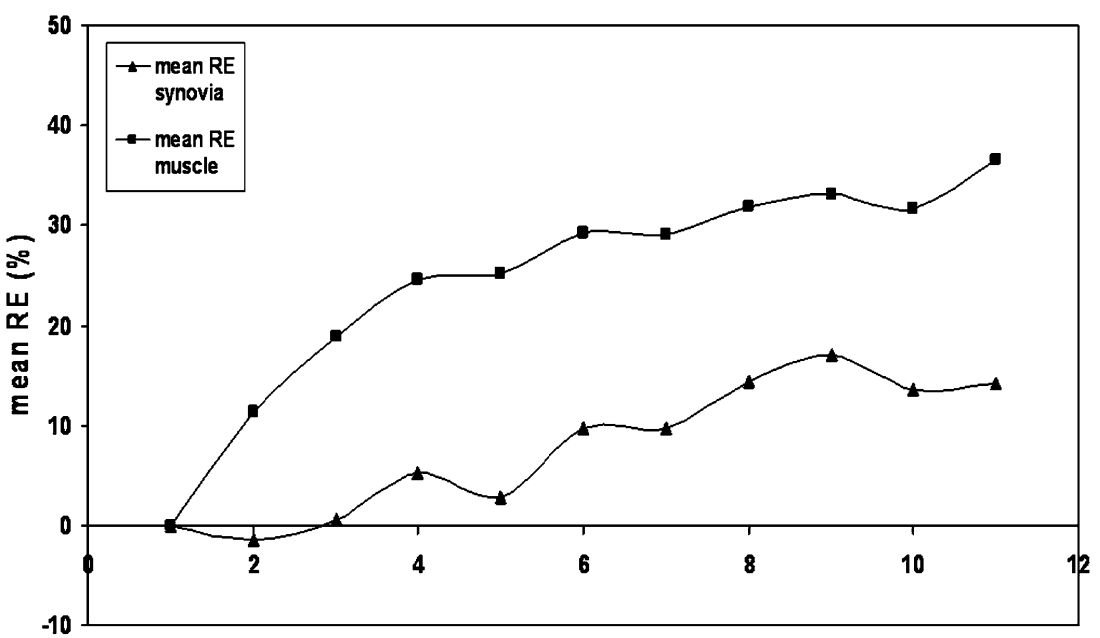

Image Number 
Table 2 Results of quantitative analysis of signal changes in the individual volunteers

\begin{tabular}{|c|c|c|c|c|c|c|c|c|c|}
\hline \multirow[t]{2}{*}{ Volunteer } & \multicolumn{3}{|c|}{ SNR pre ${ }^{\mathrm{a}}$} & \multicolumn{3}{|c|}{ SNR post ${ }^{b}$} & \multicolumn{3}{|c|}{ Relative SNR changes $(\%)$} \\
\hline & $\mathrm{T} 1 \mathrm{w}$ & $\mathrm{T} 2 \mathrm{w}$ & $\mathrm{T} 2 * \mathrm{w}$ & $\mathrm{T} 1 \mathrm{w}$ & $\mathrm{T} 2 \mathrm{w}$ & $\mathrm{T} 2 * \mathrm{w}$ & $\mathrm{T} 1 \mathrm{w}$ & $\mathrm{T} 2 \mathrm{w}$ & $\mathrm{T} 2 * \mathrm{w}$ \\
\hline 1 & 51.1 & 10.7 & 13.5 & 47.1 & 13.7 & 17.3 & -8.0 & 28.4 & 28.0 \\
\hline 2 & 23.9 & 10.7 & 11.6 & 25.0 & 10.4 & 8.7 & 4.8 & -2.4 & -25.0 \\
\hline 3 & 10.7 & 6.6 & 8.0 & 13.6 & 8.0 & 9.2 & 27.2 & 20.2 & 14.7 \\
\hline 4 & 26.5 & 23.1 & 8.5 & 24.6 & 19.6 & 8.9 & -7.1 & -15.1 & 5.8 \\
\hline 5 & 22.3 & 12.5 & 12.8 & 22.0 & 12.6 & 12.8 & -1.4 & 0.9 & -0.2 \\
\hline 6 & 11.1 & 8.8 & 11.0 & 11.4 & 9.1 & 13.4 & 2.5 & 3.1 & 21.3 \\
\hline 7 & 18.6 & 17.1 & 9.5 & 17.0 & 16.2 & 8.0 & -8.9 & -5.0 & -14.9 \\
\hline 8 & 12.6 & 8.6 & 11.1 & 14.6 & 8.1 & 10.3 & 16.0 & -5.8 & -6.6 \\
\hline 9 & 23.0 & 16.0 & 14.9 & 21.6 & 17.5 & 12.9 & -6.1 & 9.8 & -13.2 \\
\hline 10 & 19.4 & 14.1 & 21.7 & 22.7 & 12.7 & 21.1 & 16.6 & -9.5 & -2.9 \\
\hline Mean $^{c}$ & 21.9 & 12.8 & 12.2 & 22.0 & 12.8 & 12.3 & 3.6 & 2.5 & 0.7 \\
\hline SD & 11.7 & 4.9 & 4.0 & 10.0 & 4.0 & 4.2 & 12.5 & 13.5 & 16.9 \\
\hline
\end{tabular}

$S D$ standard deviation, $S N R$ signal-to-noise ratio

${ }^{a} \mathrm{SNR}$ of the synovium measured on unenhanced images

${ }^{\mathrm{b}} \mathrm{SNR}$ of the synovium measured on USPIO-enhanced images

${ }^{\mathrm{c}}$ Mean values of SNR and relative SNR changes

feasibility of macrophage-specific imaging using macrophage tagging by SPIO/USPIO has been shown in numerous animal studies $[6,11-13,26,27]$. Iron oxide nanoparticles such as SPIO and USPIO can cause pronounced MR signal effects even after application of doses in the range of micromoles/kg body weight that are detectable using standard 1.5-T scanner systems [4, $13,28]$. Since SPIO/USPIO nanoparticles are specifically taken up by cells of the mononuclear phagocytic system, SPIO/USPIO-enhanced MR imaging is a very promising approach for the detection of macrophages in inflammatory joint disease. Accordingly, promising results were shown using SPIO/USPIO-enhanced MR imaging for macrophage detection in animal models of antigen-induced arthritis [6, 11, 12, 27].

To date, however, it is not clear whether the results of animal studies can be readily translated into humans. However, before this novel imaging strategy can be tested in patients it is helpful to investigate asymptomatic volunteers in order to define normal findings, exclude nonspecific USPIO uptake, and optimize the imaging setup.

In our study we were able to confirm the findings of USPIO-enhanced MRI of nonarthritic knees in animal models. Neither qualitative nor quantitative changes in signal characteristics of the synovial tissue were observed in any of the ten knees of healthy volunteers. However, it has to be underlined that there was no higher grade knee degeneration. No synovial hyperperfusion was detected, which was also in accordance with MRI studies analyzing synovial perfusion in normal and arthritic knees [13, 14, 29].

USPIO-enhanced MRI can combine two approaches in imaging of arthritic joints: first, USPIO administration provides the possibility to quantify synovial macrophages, which correlate with disease severity; second, synovial perfusion could be assessed immediately after USPIO administration in arthritic joints. Several studies demonstrated that dynamic Gd-enhanced MRI of arthritic joints can reveal information regarding synovial perfusion and disease activity $[14,20,29,30]$ and can depict effects of treatment by showing a decrease in the enhancement rate in the arthritic knee [31, 32]. Lutz et al. [13] combined these two approaches in a rabbit model of antigen-induced arthritis using USPIO-enhanced MRI demonstrating that early synovial hyperperfusion (within the first $56 \mathrm{~s}$ after low dose bolus administration of ferumoxtran-10) and synovial macrophages can be detected in arthritic knees on USPIO-enhanced MRI. No early synovial hyperperfusion or synovial macrophages were detectable in nonarthritic control knees. Moreover, neovascularisation reflected by increased vessel density within the synovium of arthritic knees was detected following USPIO administration. To date, this approach with bolus ferumoxtran-10 administration is not transferable to humans, because ferumoxtran-10 can only be administered as slow drip infusion. Therefore, we used Gd-DOTA in our study to assess synovial perfusion. When bolus-injectable USPIO agents become available, both purposes may be accomplished with one single contrast agent.

The major limitation of our study is that we performed USPIO-enhanced MRI of the knee only in healthy volunteers. However, the aim of our study was to define normal signal characteristics and exclude nonspecific synovial signal effects, before implementing this new imaging technique in diseased patients with rheumatoid arthritis. 
Since we only analyzed a 36-h time delay between administration and imaging, our results are limited to this time frame, a 24- to 36-h time delay being the preferred one for most of the envisaged clinical indications.

\section{Conclusion}

Our results have shown that in knees of asymptomatic volunteers with absence of relevant degenerative changes and normal synovial perfusion characteristics neither visual changes nor changes with regard to the SNR of the synovium can be depicted after USPIO administration. USPIO-enhanced MRI is not hampered by nonspecific signal changes in normal control knees and may be used for assessment of knee disorders with increased macrophage activity. These results lay the foundations for future studies in patients with RA.

\section{References}

1. Weissleder R, Elizondo G, Wittenberg J, Rabito CA, Bengele HH, Josephson L (1990) Ultrasmall superparamagnetic iron oxide: characterization of a new class of contrast agents for MR imaging. Radiology 175:489-493

2. Lee SM, Lee SH, Kang HY, Baek SY, Kim SM, Shin MJ (2007) Assessment of musculoskeletal infection in rats to determine usefulness of SPIOenhanced MRI. AJR Am J Roentgenol 189:542-548

3. Gellissen J, Axmann C, Prescher A, Bohndorf K, Lodemann KP (1999) Extra- and intracellular accumulation of ultrasmall superparamagnetic iron oxides (USPIO) in experimentally induced abscesses of the peripheral soft tissues and their effects on magnetic resonance imaging. Magn Reson Imaging 17:557-567

4. Lutz AM, Weishaupt D, Persohn E et al (2005) Imaging of macrophages in softtissue infection in rats: relationship between ultrasmall superparamagnetic iron oxide dose and MR signal characteristics. Radiology 234:765-775

5. Kaim AH, Wischer T, O'Reilly T et al (2002) MR imaging with ultrasmall superparamagnetic iron oxide particles in experimental soft-tissue infections in rats. Radiology 225:808-814

6. Lutz AM, Seemayer C, Corot C et al (2004) Detection of synovial macrophages in an experimental rabbit model of antigen-induced arthritis: ultrasmall superparamagnetic iron oxideenhanced MR imaging. Radiology 233:149-157
7. Kaim AH, Jundt G, Wischer $\mathrm{T}$ et al (2003) Functional-morphologic MR imaging with ultrasmall superparamagnetic particles of iron oxide in acute and chronic soft-tissue infection: study in rats. Radiology 227:169-174

8. Kinne RW, Brauer R, Stuhlmuller B, Palombo-Kinne E, Burmester GR (2000) Macrophages in rheumatoid arthritis. Arthritis Res 2:189-202

9. Szekanecz Z, Koch AE (2007) Macrophages and their products in rheumatoid arthritis. Curr Opin Rheumatol 19:289-295

10. Firestein GS (2000) Etiology and pathogenesis of rheumatoid arthritis. In: Kelley WN, Harris ED, Ruddy S, Sledge CB (eds) Textbook of rheumatology, 6th edn. Saunders, Philadelphia, pp 921-966

11. Beckmann N, Falk R, Zurbrugg S, Dawson J, Engelhardt P (2003) Macrophage infiltration into the rat knee detected by MRI in a model of antigeninduced arthritis. Magn Reson Med 49:1047-1055

12. Dardzinski BJ, Schmithorst VJ, Holland SK et al (2001) MR imaging of murine arthritis using ultrasmall superparamagnetic iron oxide particles. Magn Reson Imaging 19:1209-1216

13. Lutz AM, Gopfert K, Jochum W, Nanz D, Frohlich JM, Weishaupt D (2006) USPIO-enhanced MR imaging for visualization of synovial hyperperfusion and detection of synovial macrophages: preliminary results in an experimental model of antigen-induced arthritis. J Magn Reson Imaging 24:657-666

14. Cimmino MA, Innocenti S, Livrone F, Magnaguagno F, Silvestri E, Garlaschi G (2003) Dynamic gadoliniumenhanced magnetic resonance imaging of the wrist in patients with rheumatoid arthritis can discriminate active from inactive disease. Arthritis Rheum 48:1207-1213

15. Noyes FR, Stabler CL (1989) A system for grading articular cartilage lesions at arthroscopy. Am J Sports Med 17:505513
16. Recht MP, Piraino DW, Paletta GA, Schils JP, Belhobek GH (1996) Accuracy of fat-suppressed threedimensional spoiled gradient-echo FLASH MR imaging in the detection of patellofemoral articular cartilage abnormalities. Radiology 198:209-212

17. Kornaat PR, Ceulemans RY, Kroon $\mathrm{HM}$ et al (2005) MRI assessment of knee osteoarthritis: knee osteoarthritis scoring system (KOSS) - interobserver and intra-observer reproducibility of a compartment-based scoring system. Skeletal Radiol 34:95-102

18. Schweitzer ME, Falk A, Berthoty D, Mitchell M, Resnick D (1992) Knee effusion: normal distribution of fluid. AJR Am J Roentgenol 159:361-363

19. Crues JV 3rd, Mink J, Levy TL, Lotysch M, Stoller DW (1987) Meniscal tears of the knee: accuracy of MR imaging. Radiology 164:445-448

20. Hodgson RJ, O'Connor P, Moots R (2008) MRI of rheumatoid arthritis image quantitation for the assessment of disease activity, progression and response to therapy. Rheumatology (Oxford) 47:13-21

21. Mulherin D, Fitzgerald O, Bresnihan B (1996) Synovial tissue macrophage populations and articular damage in rheumatoid arthritis. Arthritis Rheum 39:115-124

22. Catrina AI, Trollmo C, af Klint E et al (2005) Evidence that anti-tumor necrosis factor therapy with both etanercept and infliximab induces apoptosis in macrophages, but not lymphocytes, in rheumatoid arthritis joints: extended report. Arthritis Rheum 52:61-72 
23. Weaver AL (2004) The impact of new biologicals in the treatment of rheumatoid arthritis. Rheumatology (Oxford) 43(Suppl 3):iii17-iii23

24. Breedveld FC, Kalden JR (2004) Appropriate and effective management of rheumatoid arthritis. Ann Rheum Dis 63:627-633

25. American College of Rheumatology (2002) Guidelines for the management of rheumatoid arthritis: 2002 update. Arthritis Rheum 46:328-346

26. Simon GH, von Vopelius-Feldt J, Wendland MF et al (2006) MRI of arthritis: comparison of ultrasmall superparamagnetic iron oxide vs. GdDTPA. J Magn Reson Imaging 23:720727
27. Simon GH, von Vopelius-Feldt J, Fu Y et al (2006) Ultrasmall supraparamagnetic iron oxide-enhanced magnetic resonance imaging of antigen-induced arthritis: a comparative study between SHU 555 C, ferumoxtran-10, and ferumoxytol. Invest Radiol 41:45-51

28. Kooi ME, Cappendijk VC, Cleutjens $\mathrm{KB}$ et al (2003) Accumulation of ultrasmall superparamagnetic particles of iron oxide in human atherosclerotic plaques can be detected by in vivo magnetic resonance imaging. Circulation 107:2453-2458

29. Ostergaard M, Lorenzen I, Henriksen O (1994) Dynamic gadolinium-enhanced MR imaging in active and inactive immunoinflammatory gonarthritis. Acta Radiol 35:275-281

30. Ostergaard M, Stoltenberg M, Lovgreen-Nielsen P, Volck B, SonneHolm S, Lorenzen I (1998) Quantification of synovistis by MRI: correlation between dynamic and static gadolinium-enhanced magnetic resonance imaging and microscopic and macroscopic signs of synovial inflammation. Magn Reson Imaging 16:743-754
31. Tam LS, Griffith JF, Yu AB, Li TK, Li EK (2007) Rapid improvement in rheumatoid arthritis patients on combination of methotrexate and infliximab: clinical and magnetic resonance imaging evaluation. Clin Rheumatol 26:941-946

32. Ostergaard M, Stoltenberg M, Henriksen O, Lorenzen I (1996) Quantitative assessment of synovial inflammation by dynamic gadoliniumenhanced magnetic resonance imaging. A study of the effect of intra-articular methylprednisolone on the rate of early synovial enhancement. Br J Rheumatol 35:50-59 